REJ - Revista de Estudios de la Justicia - No 9 - Año 2007

\title{
DERECHOS FUNDAMENTALES Y DERECHO PENAL
}

\author{
Antonio Bascuñán Rodríguez.
}

1. El paradigma clásico y su inversión; 1.1. Consideraciones generales; 1.2. El concepto material de delito bajo el paradigma clásico; 2. Derechos fundamentales y merecimiento de pena; 2.1. De la norma de comportamiento a la norma punitiva; 2.2. Deberes supralegales de punición; 2.3. Problemas originados por la definición supralegal del merecimiento de pena; 3. Derechos fundamentales y necesidad de la ejecución de la pena.

\section{El paradigma clásico y su inversión}

\subsection{Consideraciones generales.}

La hipótesis de trabajo de la que parten estas consideraciones es la constatación de un cambio en el discurso relativo a las relaciones entre los derechos fundamentales y la potestad punitiva del Estado (en adelante, "ius puniendi’).

El discurso heredado de la Ilustración y el Constitucionalismo (en adelante, el "paradigma clásico") puede resumirse en las siguientes dos tesis: (1) el ius puniendi es una fuente de peligro para los derechos fundamentales, (2) es necesario contar con arreglos institucionales para controlar ese peligro.

Estas dos tesis presuponen una afirmación previa de la legitimidad del ius puniendi. Para el paradigma clásico, el hecho de que el ejercicio del ius puniendi se concrete inevitablemente en la afectación de intereses individuales fundamentales (la libertad, la intimidad, el patrimonio, y en los sistemas jurídicos que no se someten a un principio de proporcionalidad exigente, incluso la vida) no implica sin más su ilegitimidad. El paradigma clásico es liberal, no anarquista. Desde su punto de vista, esa afectación es legítima en la medida en que resulta necesaria para mantener la vigencia de un orden normativo legítimo.

Pero la legitimación inicial del ius puniendi es una legitimación provisoria. No asegura sin más su legitimidad, sino que lo somete a una dialéctica de legitimación. En el marco de esa dialéctica, el ejercicio del ius puniendi políticamente legitimado queda sujeto a estándares jurídicos de legitimación negativa particularmente estrictos. Esos estándares normativos forman parte del núcleo firme del catálogo de derechos fundamentales y sus arreglos institucionales. En este contexto de aplicación, los derechos fundamentales constituyen el marco normativo para el control judicial del ejercicio del ius puniendi.

\footnotetext{
* Profesor de Derecho Penal y Procesal Penal en la Universidad Adolfo Ibáñez, Profesor Asistente
} de Derecho Penal en la Universidad de Chile. 
El habeas corpus es el arreglo institucional más obvio de control del ius puniendi, en la medida en que la privación de libertad es el modo primario de su ejercicio, tanto en lo que respecta a las normas punitivas como al proceso penal. La prohibición de la aplicación retroactiva de las normas punitivas desfavorables al destinatario y de la vaguedad o indeterminación de su formulación son dos garantías fundamentales, compartidas por el sistema jurídico norteamericano y el puertorriqueño, los sistemas jurídicos europeo-continentales y los sistemas jurídicos sudamericanos. La estricta vinculación de la condena a una disposición legislativa es otra garantía fundamental de los sistemas jurídicos europeocontinentales y sudamericanos, y, en un rango infraconstitucional, también del sistema jurídico puertorriqueño.

Más allá de las garantías anteriores, en mayor o menor medida susceptibles de ser consideradas como estándares formales, el desarrollo del marco normativo supralegal ha producido también en ese ámbito el surgimiento de estándares materiales de control judicial del ius puniendi. La prohibición de penas crueles e inusuales, o de penas o castigos crueles, inhumanos o degradantes, otra de esas garantías fundamentales compartida por todos los sistemas, es el estándar material mínimo. Los estándares materiales de mayor aliento, y por lo mismo más inciertos en su peso específico y operatividad concreta, se encuentran en los principios de culpabilidad y proporcionalidad. El primero es un principio de legitimación retrospectiva (y que incluye la proporcionalidad estricta o proporcionalidad conforme a la culpa por el hecho), el segundo es un principio de legitimación prospectiva conforme a la racionalidad de los fines, que incluye el examen de la adecuación y necesidad de la pena como medio de control social, y la preponderancia del fin de protección respecto de su naturaleza y cuantía.

En conjunto, los estándares normativos antedichos constituyen límites normativos del ejercicio del ius puniendi por parte del Estado-Adjudicador y del Estado-Administrador, y, en un esquema constitucional de revisión judicial, también límites supralegales relativos al ejercicio del ius puniendi por parte del Estado-Legislador. Los derechos fundamentales configuran así los límites del derecho penal.

El cambio operado en el discurso de los derechos fundamentales representa una inversión del paradigma clásico. En el nuevo paradigma, los derechos fundamentales ya no representan un marco limitativo del ejercicio del ius puniendi, sino su impulso. El ius puniendi no es un peligro, sino un medio de protección de los derechos fundamentales. De los derechos fundamentales ya no se derivan prohibiciones de su ejercicio, sino deberes de punición.

Hasta donde se alcanza a ver, esta inversión se ha producido de dos modos. 
El primero es la postulación de deberes de protección de los derechos fundamentales, dirigidos al Estado. El paradigma clásico concibe los deberes correlativos a los derechos fundamentales como deberes de omisión, es decir, como prohibiciones de afectación. El nuevo paradigma agrega como deberes correlativos de los derechos fundamentales deberes de prestaciones positivas, que abarcan las prestaciones normativas (= deber de protección normativa). Este nuevo paradigma es propio del derecho internacional de los derechos humanos y se ha consolidado también en jurisdicciones constitucionales nacionales, principalmente la alemana.

La segunda forma de inversión del paradigma clásico es la consolidación en el derecho internacional de mandatos (imperativos) de punición, basados en la consideración de la intangibilidad de (o la vigencia de las normas sobre) los derechos fundamentales como fin de protección. En este nuevo discurso, no es el ejercicio del ius puniendi sino su omisión lo que pasa a quedar sujeto a control judicial, debido a la postulación del mandato de punición.

Ambos contextos son reconducibles a un mismo paradigma. El contexto del derecho penal internacional no es más que un caso especial de aplicación institucional del programa normativo que es propio del contexto de los deberes de protección. El surgimiento de mandatos supralegales de punición es la expresión institucional y formal de un momento de la concreción del contenido normativo posible de los deberes de protección. Esa formalización institucional -como toda otra- introduce una cisura en la cadena argumentativa que va del reconocimiento del derecho fundamental a la postulación de un mandato de punición, dejando los pasos argumentativos previos en un contexto de fundamentación, y reduciendo el contexto de aplicación al control del cumplimiento del mandato de punición. La cuestión de si esa cisura debilita o refuerza la potencia expansiva del nuevo paradigma sólo puede tener una respuesta pragmática. Su constatación puede dar lugar a un principio de auto-constreñimiento judicial o servir de apoyo institucional para el desarrollo de nuevos mandatos de punición. En eso, el nuevo paradigma está sometido a la misma tensión entre el efecto expansivo de las consideraciones a simili y el efecto restrictivo de las consideraciones a contrario que es inherente al desarrollo jurisprudencial de cualquier sistema jurídico.

La tesis de que este es un nuevo paradigma de discurso acerca de las relaciones entre los derechos fundamentales y el derecho penal ha sido objetada. En su contra se hace ver que la postulación de los derechos fundamentales como criterio último de legitimación del orden jurídico estatal siempre ha sido acompañada por la consideración del aseguramiento de la vigencia de esos derechos como finalidad principal de la constitución del Estado. Si la seguridad del ciudadano es el fin del estado civil, entonces la protección de los derechos fundamentales es un deber del Estado. El paradigma clásico implicaría así deberes de protección. 
En el plano de la legitimación política esta tesis puede ser admitida como en lo esencial correcta. Por cierto, la correlación entre la seguridad del ciudadano y las formas institucionales específicas de reacción (o acción preventiva) del Estado contra la frustración de sus expectativas de intangibilidad es una cuestión problemática. Pero reduciendo la tesis a la aseveración de que la seguridad del ciudadano exige alguna forma razonable de acción o reacción estatal, resulta difícil objetar que esa exigencia es un deber fundamental del Estado.

Lo dicho no significa, sin embargo, que el deber de protección de los intereses fundamentales del ciudadano sea institucionalmente equiparable a la prohibición de afectación de esos intereses. Es esta equiparación institucional, y no una equiparación en el puro plano de la justicia política, lo que aquí está en juego. La postulación de un deber de protección de los derechos fundamentales, que puede incluir un deber de ejercicio del ius puniendi, como deber institucionalmente equiparable a la prohibición de afectación de esos derechos, implica dos consecuencias básicas:

(a) la exigencia de arreglos institucionales para el control judicial del cumplimiento de ese deber de ejercicio del ius puniendi, equiparables a los arreglos propios del control judicial de su limitación;

(b) la aceptación de la posibilidad de un conflicto entre un deber de ejercicio del ius puniendi y cualquiera de los estándares normativos limitadores del mismo, que eventualmente pudiera resolverse a favor del primero.

Ninguna de estas dos consecuencias son imputables al paradigma clásico.

En el paradigma clásico, ningún fundamento de legitimación positiva del ius puniendi puede compensar la infracción de un principio limitador. Esos principios operan como límites del ejercicio de una potestad punitiva asumida ya como legítima prima facie. En este modelo, los criterios negativos de legitimación no están sujetos a ponderación con criterios positivos.

En el paradigma clásico, los arreglos institucionales surgen para controlar judicialmente una desviación específica del poder del Estado respecto de su finalidad legitimatoria, no cualquier desviación. Es la afectación del derecho fundamental por parte del Estado con ocasión del ejercicio de sus competencias normativas, y no la omisión de su protección mediante ese ejercicio, la desviación a cuyo control se orientan específicamente los arreglos institucionales judiciales. La justificación de este tratamiento diferenciado de las formas de control de la desviación del poder del Estado - control judicial de la infracción de la prohibición de afectación, control político de la infracción de deber de protección- puede impugnarse en el plano de la justicia política. Pero es un hecho histórico que el reconocimiento o establecimiento de normas jurídicas supralegales sobre derechos fundamentales tuvo esa orientación específica, y por lo tanto obedeció a esa diferenciación. 
No es pues el carácter históricamente novedoso de este paradigma que incorpora deberes de protección, sino su carácter conceptualmente inconsistente con el paradigma clásico, lo que puede dar lugar a una objeción. En todo caso, la objeción se reduce a la diferenciación de los arreglos judiciales de control del cumplimiento de los deberes. Pues en lo que respecta a la equiparación entre mandatos de protección penal y principios limitadores del ius puniendi la inconsistencia conceptual es manifiesta. Por esta razón, la tesis de la equiparación no es postulada -al menos no abiertamente- por el nuevo paradigma. Eso requiere una reformulación del modo en que los mandatos de punición, en tanto consecuencias de deberes de protección, se incorporan al marco supralegal de los derechos fundamentales.

La valoración de esta inversión del paradigma depende, ciertamente, de las premisas que sean asumidas de entre el intrincado complejo de principios de justicia política y de metodología de adjudicación, así como de concreciones institucionales, que forman una cultura jurídica. Así, por ejemplo, para quien apele a los derechos fundamentales como únicos criterios últimos de legitimación del orden jurídico, entienda la legislación y la adjudicación como un proceso de concreción del contenido normativo de esos criterios de legitimación y sustente una teoría retribucionista de la pena, la postulación de un deber de sanción penal de la violación de los derechos fundamentales tendrá que parecerle algo cuasi tautológico. Mucho de esto está presente en el cambio de paradigma.

El discurso de los derechos humanos ha pasado a ocupar una posición preeminente en el plano de la teoría de la justicia. La apelación a un derecho fundamental confiere al planteamiento práctico que la efectúa un peso cognitivo considerable, que es particularmente relevante en el contexto de una discusión moral que tiene lugar bajo el principio de la legitimidad inicial de concepciones contrapuestas. La agenda de los organismos internacionales para la promoción de los derechos humanos no hace distinciones firmes entre las diferentes formas posibles de su concreción, difuminando los constreñimientos específicos de la justificación jurídica. De modo semejante, la conversión metodológica de los derechos fundamentales, de derechos subjetivos en valores o principios objetivos, produce una dinámica de expansión institucional de su operatividad que es en muchos sentidos equiparable al efecto de erosión de los márgenes de la autonomía colectiva de la comunidad democrática que trae consigo la expansión del derecho internacional. Finalmente, la última década del siglo XX ha sido testigo de un agresivo renacimiento de la fundamentación retribucionista de la sanción penal, y, por cierto, de su asunción en un nivel francamente irreflexivo -como le corresponde- con ocasión del surgimiento del derecho penal internacional.

Este entrecruzamiento de variables que inciden en la valoración de la inversión del paradigma clásico hace que la asunción de una actitud crítica frente al fenómeno, como es mi caso personal, se vea expuesta casi inevitablemente a malentendidos. Para reducir ese riesgo en la medida de lo evitable, las líneas que 
siguen se sujetan a una distinción básica, como es la que se hace entre el merecimiento de pena y la necesidad de la ejecución de la pena (merecida).

En la Sección 2, me concentraré en cuestiones problemáticas del merecimiento de pena, entendiendo por tal la fundamentación política de una norma punitiva a partir de una norma de comportamiento. Esto implica la valoración de la infracción de esa norma de comportamiento como un comportamiento respecto del cual es prospectiva o retrospectivamente (es decir, preventiva o retributivamente) justificable la imputación de una sanción penal como consecuencia. En esa sección, partiré de la base que un derecho fundamental es una justificación políticamente plausible de una norma de comportamiento o de un deber de establecerla y examinaré la cuestión de qué consecuencias pueden atribuirse analítica y políticamente a ello. Esta pregunta es importante para desarrollar un esquema diferenciado de análisis de los efectos de los deberes de protección. Este análisis diferenciado será desarrollado con especial cuidado para el tratamiento de los deberes explícitos de punición que han sido consagrados en el derecho supralegal. Finalizaré esta sección haciendo hincapié en algunos problemas relacionados con los deberes supralegales de punición, en particular los del derecho penal internacional de los derechos humanos.

En la Sección 3, de extensión mucho más reducida, examinaré algunas cuestiones problemáticas de la necesidad de ejecución de la pena de las infracciones a las normas de comportamiento merecedoras de pena. La pregunta en este caso se concentra en la admisibilidad de la prescindencia institucionalizada de la pena frente a infracciones pasadas de normas de comportamiento subyacentes normas punitivas (amnistía, indulto, prescripción). Mi propósito en esta sección es el de esclarecer por qué tratándose de cierta clase de delitos contra los derechos fundamentales hay razones particularmente poderosas para la necesidad de la pena. Con todo, defenderé la tesis de que estas razones no precluyen absolutamente la plausibilidad de consideraciones justificatorias de la impunidad, y que la defensa de esta tesis es el mínimo de racionalidad ilustrada que cualquier comunidad debe mantener para que sus prácticas políticas sean legítimas.

Antes de pasar a esas secciones, quisiera brevemente despejar una cuestión, que es importante para los que participamos de la cultura jurídico-penal europea continental: la conexión entre los derechos fundamentales y el concepto material del delito o concepción del injusto penal como afectación de un bien jurídico.

\subsection{El concepto material de delito bajo el paradigma clásico.}

Conforme al discurso usual de la legitimación del ius puniendi en la cultura europea continental, la pena es legítima exclusivamente como medio de protección de un bien jurídico (más estricta -y circularmente-, "bien jurídicopenal"). La idea de que los derechos fundamentales constituyen criterios de 
identificación y concreción de bienes jurídicos, merecedores de protección mediante la pena, se encuentra en el origen de este planteamiento. La teoría de Feuerbach, que tuvo carácter fundacional para el derecho penal moderno europeo-continental, consistía precisamente en definir un "crimen" como "lesión de un derecho". El cambio posterior de terminología se debió a un intento conservador de repostulación de los criterios de identificación de los objetos merecedores de protección penal, y a la posterior ineptitud filosófica de los tratadistas de derecho penal, que continuaron usando el término "bien" para designar abreviadamente el resultado concreto al que llegaban aplicando un conjunto de criterios liberales (j!) de fundamentación del merecimiento de pena.

Esta vinculación entre la noción del delito como lesión de un bien jurídico y los derechos fundamentales ha experimentado un nuevo reforzamiento en virtud del desarrollo de la teoría constitucional del bien jurídico, que remite al marco jurídico supralegal para la identificación de los bienes jurídicos merecedores de protección. En esa remisión se pretende realizar el sueño de la teoría del bien jurídico, en la medida que ahora se cuenta criterios que son a la vez independientes de la voluntad del legislador y jurídicamente vinculantes. Esta concepción es naturalmente compartida por el nuevo de paradigma de discurso entre los derechos fundamentales y el derecho penal. Sin embargo, detrás de esa coincidencia se esconde una discrepancia fundamental.

Para el principio de la exclusiva protección de bienes jurídicos, la referencia a la Constitución -o, dicho más precisamente, al orden constitucional de los bienes fundamentales- cumple una función negativa. Conforme a este principio, lo que no sea reconocible como parte integrante de ese orden no es merecedor de protección penal. Por el contrario, lo que pretende afirmar el nuevo paradigma es que un derecho fundamental constituye por lo mismo un bien merecedor y necesitado de protección penal. Este enunciado no se deduce del anterior: una condición necesaria no es, sin más, también una condición suficiente.

La evolución de la teoría constitucional del bien jurídico ha puesto de manifiesto este hecho, al reconocer que ella sólo es capaz de ofrecer un concepto material de delito que permite justificar con base en la Constitución qué intereses no son legítimamente perseguibles mediante la pena.

El desentrañamiento de la auténtica función de la teoría constitucional del bien jurídico requiere, por cierto, ser mucho más estricto de lo que ella está dispuesta a admitir. Apreciado rigurosamente este punto, lo único que puede afirmarse con base en la Constitución es que (1) una norma de comportamiento es ilegítima por afectar inadmisiblemente el ejercicio de derechos fundamentales, en virtud de su intromisión en ámbitos de autonomía constitucionalmente garantizados, o bien que (2) una norma punitiva es ilegítima, no obstante que su fin sea reforzar la vigencia de una norma de comportamiento legítima, porque no satisface los requisitos limitadores del ius puniendi arriba enunciados. 
En el caso de (1), se está frente a una cuestión que no es específicamente penal, sino que es compartida por todas las ramas del ordenamiento jurídico en las cuales se formulan normas de comportamiento. Cuando el discurso jurídico-penal sostiene que tal o cual norma punitiva es ilegítima porque no protege bien jurídico alguno, hay que traducir esa afirmación -harto esotérica por lo demás- en la más comprensible aserción de que se trata de una intervención del Estado que afecta un interés de libertad de una persona sin justificación racional o que afecta en su núcleo esencial ámbitos de autonomía específicamente garantizados. Estas consecuencias que el discurso penal pretende deducir del concepto de bien jurídico para el ejercicio del ius puniendi no se reducen al ius puniendi, ni se deducen del concepto de bien jurídico. Son consecuencias que los derechos fundamentales producen para todos los ámbitos de la actuación del Estado.

En el caso de (2), sí se está frente a una cuestión de legitimación propia del ius puniendi, referida a la satisfacción de las garantías específicas que constituyen límites a su ejercicio. Pero aquí el concepto de bien jurídico y su formulación como presunto estándar legitimatorio específico -el así denominado "principio de lesividad"-, no tiene apoyo alguno en el derecho constitucional o internacional con independencia del principio de la proporcionalidad (prospectiva). En este plano, la noción de "bien jurídico" no es más que una concreción para hacer operativo el principio de proporcionalidad stricto sensu, o juicio de ponderación entre el interés de afectación (o sea, el interés afectado con la substanciación del proceso penal y la imposición y ejecución de la pena) y el interés de protección (o sea, el interés afectado con la comisión del delito). Insistir en la vigencia de un principio de lesividad no es más que postular un examen particularmente riguroso de proporcionalidad stricto sensu. $O$ sea, algo que ninguna jurisdicción constitucional sensata postula.

La postulación del principio de exclusiva protección de bienes jurídicos (lesividad) como estándar independiente de limitación del ius puniendi es la mejor expresión de la falta de vocación del discurso jurídico-penal por asegurar la distinción entre las cuestiones de política-criminal y las cuestiones de dogmática constitucional. Pero esta es una distinción de la que no puede prescindir una democracia.

\section{Derechos fundamentales y merecimiento de pena.}

\subsection{De la norma de comportamiento a la norma punitiva.}

El paso de una norma que configura un derecho fundamental a una norma de comportamiento, que prohíbe a un (in)determinado círculo de destinatarios la afectación de ese derecho, es problemático. En su sentido originario, las normas sobre derechos fundamentales son reglas de desconocimiento, es decir, reglas que configuran condiciones negativas vinculadas a un criterio de validez. Su función 
práctica es la de una norma de valoración judicial de un acto realizado por órganos o agentes del Estado, conducente a la invalidación de ese acto y el restablecimiento del estado de cosas afectado por ese acto. Sólo derivativamente, es decir, solamente en función de la evitación de esa valoración adversa, esas reglas pueden ser consideradas desde la perspectiva de los detentadores de potestades públicas, como normas de determinación, es decir, como normas de comportamiento.

La solución de ese problema de fundamentación puede seguir diversos caminos argumentativos. Uno de ellos consiste en la postulación de un deber de protección, y a partir de él, de un deber de protección normativa, en cuyo cumplimiento se establece una norma de comportamiento que prohíbe su afectación. Otro camino es el desarrollo de una dimensión objetiva de valor o principio, que sirve de fundamentación para el establecimiento o incluso reconocimiento judicial de una norma de comportamiento, que prohíbe su afectación. Finalmente, está el caso chileno, que ha seguido el camino brutal de considerar a los derechos fundamentales como fuentes directas de prohibiciones de afectación erga omnes, constitutivas primariamente de normas de comportamiento, y en su virtud, de normas de valoración.

Este problema argumentativo no es propio del nivel de reflexión del contexto al que pertenecen estas páginas, sino que corresponde a otros ámbitos de la discusión en torno a los derechos fundamentales. Quien niegue toda posibilidad de deducir normas de comportamiento o deberes de establecimiento de normas de comportamiento a partir de las normas de derechos fundamentales se cierra a la discusión sobre la fundamentación judicialmente operativa del ius puniendi en los derechos fundamentales. Quien la acepte en alguna medida, en esa misma medida se abre a esa discusión. Por consiguiente, parto como hipótesis de trabajo de la postulación de una norma de comportamiento, o de un deber de establecer esa norma, como conclusión de un razonamiento judicialmente operativo que tiene su premisa en una norma de derecho fundamental.

La pregunta que esa postulación plantea se refiere a las consecuencias del reconocimiento de una norma de comportamiento o de un deber de establecerla, esto es, las consecuencias deónticas que se deducen, ya sea de la mera afirmación de la existencia de esa norma o deber, o bien de esa afirmación en conjunción con otros principios cuya existencia en un sistema jurídico pueda tenerse por no problemática.

¿Cuáles son las consecuencias que se deducen del reconocimiento de una norma de comportamiento o del deber de establecerla? Analíticamente, la respuesta depende del criterio de reconocimiento que se siga en un sistema jurídico. En un sistema que no es reflexivo, es decir, que carece de reglas jurídicas de segundo nivel, la existencia de la norma dependerá de la constatación de alguna (eventual) forma de reacción social frente a su (eventual) infracción. Pero los sistemas jurídicos modernos son sistemas reflexivos, y por lo tanto la existencia de 
una norma puede reconocerse mediante el uso de una regla que atribuya a ciertos actos el sentido de crear esa norma. Bajo un criterio procedimental de validez, la afirmación de la pertenencia de la norma al sistema se remite a su génesis y no las (eventuales) consecuencias de su infracción. Por lo tanto, en un sistema jurídico moderno, la deducción de consecuencias imputables al caso de la infracción de la norma de comportamiento requiere la adición de otras premisas normativas. El modo como usualmente se hace referencia a estas premisas adicionales en los deberes de regulación es exigiendo no simplemente la establecimiento de una norma como norma válidamente perteneciente al sistema, sino como "norma efectiva", es decir, como norma cuya infracción acarrea consecuencias, lo que presupone que le sean normativamente imputables esas consecuencias.

Un primer principio jurídico adicional evidente es el desconocimiento sustantivo o procedimental de las pretensiones jurídicas de actos realizados u omisiones incurridas con infracción a esa norma. En principio, es claro que el sistema jurídico no puede reconocer las pretensiones normativas contrarias a normas fundamentales, sin incurrir en contradicción. Desde un punto de vista sustantivo, el desconocimiento se concreta en la inadmisibilidad prima facie de la justificación de la infracción a la norma. Este efecto ciertamente presupone que la infracción a la norma acarree alguna otra consecuencia adicional en el sistema jurídico, de modo que tengan sentido la alegación de justificación del imputado. Pero mientras esas otras consecuencias son todavía contingentes desde el punto de vista de la norma de comportamiento, inadmisibilidad prima facie de la justificación es una consecuencia necesaria del reconocimiento de una norma de comportamiento. La declaración de un comportamiento como prohibido en tal calidad, excluye la apreciación de causas de justificación que eximan de las consecuencias que el sistema pueda imputar a esos comportamientos. Este efecto puede ser eventualmente revertido, siempre que el propio ordenamiento admita casos de conflicto con otros principios que eventualmente pudieran resolverse a favor de éstos, conforme al tratamiento del conflicto de intereses. Desde un punto de vista procedimental, el desconocimiento se manifiesta en todas las formas de denegación del reforzamiento institucional de pretendidos efectos jurídicos del acto de declaración de voluntad realizado con infracción a la norma de comportamiento, como su invalidación o inoponibilidad. Para nada es evidente, por cierto, la respuesta a la pregunta de qué órganos estatales son competentes para constatar la infracción y declarar este desconocimiento procedimental. Pero puede partirse de la premisa de que un sistema jurídico moderno cuenta con reglas de atribución de competencia (reglas de adjudicación) que pueden satisfacer esa incertidumbre. Con esta salvedad, el desconocimiento procedimental puede ser considerado como una consecuencia práctica de la infracción de una norma de comportamiento fundamental.

Otro principio jurídico adicional evidente es la autorización (permiso) del impedimento de la infracción o de la perduración del estado de cosas producido como resultado de ella, en algún nivel de las posibles reacciones sociales. Un nivel es el de la intervención policial. Otro, el de la autotutela, incluyendo la legítima 
defensa propia o de terceros, el estado de necesidad defensivo y las reglas de impunidad de la coacción violenta o conminatoria destinada a impedir un acto antijurídico. Otro finalmente, el de las acciones judiciales, en particular las medidas protectivas de urgencia. Sin duda que en este caso es mucho más difícil postular un principio general con algún contenido normativo determinado. Cuál sea el nivel y el alcance en que él se concreta, depende un grado mucho mayor de las determinaciones institucionales de cada sistema jurídico. Pero puede asumirse que en algún nivel y en alguna medida esa autorización es una consecuencia práctica de la infracción de una norma de comportamiento fundamental.

Finalmente, también puede asumirse como principio general adicional el deber de reparación del mal irrogado o restablecimiento al estado anterior a la infracción de la norma de comportamiento, ya sea en la especie o por equivalencia. Por cierto, la imputación de esta consecuencia depende de la concurrencia de requisitos adicionales a la pura antijuricidad formal, exigidos por esta institución del derecho privado o público. La determinación de esos requisitos adicionales sigue criterios más o menos generalizados entre los distintos sistemas jurídicos. Con esta precaución, puede asumirse que la reparación es una consecuencia de la infracción de una norma de comportamiento.

Fuera del desconocimiento sustantivo y procedimental, la autorización del impedimento y la reparación del mal irrogado, no me parece que existan otras consecuencias prácticas, susceptibles de imposición forzosa contra la voluntad del infractor, que puedan imputarse (en alguna medida) a la infracción de una norma de comportamiento o al contenido de un deber de establecer dicha norma.

En particular, la sanción no es una consecuencia imputable sin más a la infracción de una norma de comportamiento. Es claro que una norma sancionatoria es analíticamente inderivable de una mera norma de comportamiento. La sanción es la afectación de un interés relevante del destinatario de una norma de comportamiento, imputada como consecuencia de su infracción. Esta imputación sólo es posible en virtud de una decisión normativa adicional, independiente de la norma de comportamiento. Es posible deducir una norma de comportamiento a partir de una norma punitiva, pero no a la inversa. Y tampoco existe un principio general de imputación de una sanción genérica (o un repertorio de ellas) a la infracción de una norma de comportamiento fundamental, que sea análogo a los principios de desconocimiento sustantivo o procedimental, autorización de impedimento o reparación del mal irrogado.

A primera vista, la aseveración anterior resulta paradojal, pues ella aparece como contradictoria con la concepción del derecho como un orden normativo coercitivo. Esta paradoja aparente se debe, naturalmente, a la confusión usual entre el concepto de coacción de Austin y el de Kelsen. La distinción entre norma de comportamiento y norma sancionatoria es contradictoria con el primer concepto de coacción, conforme al cual, si una norma en definitiva no conlleva una sanción para el caso de su contravención entonces no puede ser considerada 
como una de norma jurídica. Pero, como es sabido, este es un problema de ese concepto de norma jurídica. El único concepto de coercitividad que puede valer como característica del sistema jurídico es el de la coacción al servicio de la imposición de una consecuencia jurídica contra la voluntad del afectado, cualquiera que sea esa consecuencia.

La estrecha relación que usualmente se atribuye a la norma de comportamiento y la norma sancionatoria en el pensamiento jurídico no es, pues, analítica, sino de naturaleza puramente funcional. La sanción es una forma usual de asegurar la vigencia de una expectativa normativa. Por esta razón, la norma sancionatoria es también una forma usual de expresión de la norma de comportamiento.

Que entre la norma de comportamiento y la norma sancionatoria exista una relación puramente funcional significa que la afirmación de un deber de sancionar a partir del reconocimiento de un deber de establecer una norma de comportamiento se basa por entero en el principio de la proporcionalidad. Esto quiere decir, que la existencia de un deber de prestación normativa implica únicamente una autorización para el establecimiento de sanciones, subordinada siempre a la prohibición de exceso. Sólo en conjunción con otras consideraciones normativas, la prohibición de defecto puede justificar un deber de sancionar como consecuencia de un deber de regular.

Todo establecimiento de una norma sancionatoria implica una nueva afectación de derechos fundamentales. La sanción estatal es un reproche que al hacerse efectivo que conlleva una afectación de derechos fundamentales distinta y adicional a la restricción de libertad que se deriva de una norma de comportamiento. De aquí que, en tanto acto que afecta o pone en peligro los derechos fundamentales, la norma sancionatoria está sujeta a un nuevo y más intenso examen bajo los derechos de impugnación conforme el esquema del principio de proporcionalidad. Esta es la diferencia fundamental entre la satisfacción de un deber de protección mediante una norma de comportamiento (con sus consecuencias necesarias o usuales) y su satisfacción mediante una norma sancionatoria. Esta consideración es también lo que permite diferenciar un mandato de sanción de un mandato de punición.

Analíticamente consideradas, no hay diferencia categoriales entre la norma sancionatoria y la norma punitiva. Desde un punto de vista analítico, la pena es una clase especial de sanción. La diferencia es, en principio, cuantitativa. La pena es una sanción que afecta de modo particularmente intenso los derechos fundamentales del destinatario de la norma punitiva. Esta intensidad da lugar sin embargo a una diferencia que desde el punto de vista de la justicia política puede considerarse cualitativa entre la pena y cualquier otra sanción, por dos razones.

En primer lugar, por la entidad del derecho fundamental afectado y la gravedad de su afectación en relación con el libre desarrollo de la personalidad del 
destinatario de la norma punitiva. Este es, esencialmente, el caso de las penas privativas de libertad, que conllevan una afectación masiva de los derechos de la personalidad, incluyendo la intimidad, y el plan personal de vida del condenado.

En segundo lugar, la diferencia cualitativa se basa en las posibilidades de afectación de derechos fundamentales autorizadas por la substanciación del proceso en el cual se acredita la responsabilidad por la infracción de la norma de comportamiento que subyace a la norma punitiva y se dicta la condena, cualquiera sea la naturaleza de la pena.

Esta diferencia cualitativa entre cualquier ejercicio de potestad normativa sancionatoria y el ejercicio del ius puniendi es lo que origina el conjunto de garantías limitativas del mismo, mencionadas inicialmente. Ese marco garantístico prohíbe la deducibilidad de una norma punitiva a partir de una norma de comportamiento (principio de legalidad). Por otra parte, frente a este marco garantístico todas las fundamentaciones del merecimiento de pena están igualmente sujetas a examen (principios de culpabilidad y proporcionalidad).

No cabe duda que la reconducción del impulso político criminal a un interés cuya protección es impuesta por normas fundamentales supralegales tiene un rol que desempeñar en la justificación de su legitimidad bajo el principio de proporcionalidad. Pero ello en ningún caso prejuzga en términos absolutos el merecimiento de pena. Muy por el contrario, conforme al esquema del principio de la proporcionalidad debe asumirse que la peculiar entidad de la pena intensifica exponencialmente el rol de la prohibición de exceso y debilita correlativamente el rol de la prohibición de defecto. Por esta razón, la apertura a consideraciones de política jurídica alternativas al ius puniendi debe ser asumida como una opción que es siempre posible. Debido a lo anterior, la justificación de un deber de punición en base la conjunción entre un deber de regulación y otras consideraciones normativas resulta particularmente difícil, por no decir prácticamente imposible, si ello no involucra una aplicación del principio de la igualdad.

En resumen, de la existencia de una norma de comportamiento no puede deducirse una norma punitiva, ni puede deducirse en principio un deber jurídico de establecimiento de una norma punitiva a partir de un deber jurídico de establecimiento de una norma de comportamiento.

\subsection{Deberes supralegales de punición.}

La existencia de deberes explícitos de punición en el derecho supralegal viene a resolver precisamente la dificultad anterior, sirviendo de justificación sustitutiva al complejo de razones que deberían tomarse en consideración para derivar un deber de sancionar penalmente como consecuencia de un deber de 
regular. Este es el caso, en la Constitución chilena, del Art. $9^{\circ}$ inciso segundo ${ }^{1}$, así como de un considerable número de casos del el derecho internacional humanitario ${ }^{2}$ y el derecho internacional de los derechos humanos ${ }^{3}$.

En todos estos casos, la existencia de un mandato explícito de punición es un prejuzgamiento afirmativo de la cuestión político-criminal del merecimiento de la pena. Un Estado que incorpora estos mandatos en su ordenamiento jurídico

\footnotetext{
1 "Una ley de quórum calificado determinará las conductas terroristas y su penalidad" (Art. 9 inciso segundo Const. Pol.).

2 Por ejemplo, el I Convenio de Ginebra, para Mejorar la Suerte de los Heridos y los Enfermos de las Fuerzas Armadas en Campaña (12 de Agosto de 1949.), en su Art, 49 ("Las Altas Partes Contratantes se comprometen a tomar todas las oportunas medidas legislativas para determinar las adecuadas sanciones penales que se han de aplicar a las personas que hayan cometido, o dado orden de cometer, una cualquiera de las infracciones graves contra el presente Convenio definidas en el artículo siguiente.”). De forma análoga, las siguientes disposiciones: II Convenio de Ginebra, para Mejorar la suerte de los Heridos, Enfermos y Náufragos de las fuerzas Armadas en el Mar (12 de Agosto de 1949), Arts. 50 y 51; III Convenio de Ginebra, sobre el Tratamiento de los Prisioneros de Guerra (12 de Agosto de 1949), Arts. 129, 130; IV Convenio de Ginebra, relativo a la Protección a las Personas Civiles en Tiempos de Guerra (12 de Agosto de 1949), Arts. 147, 148; I Protocolo Adicional a los Convenios de Ginebra, relativo a la Protección de las Víctimas de los Conflictos Armados Internacionales (8 de Junio de 1977), Art. 85.

3 Por ejemplo, la Convención para la Prevención y Sanción del Delito de Genocidio (9 de Diciembre de 1948), Art. V, segunda parte ([deber de]" "establecer sanciones penales eficaces para castigar a las personas culpables de genocidio o de cualquier otro de los actos enumerados en el artículo III"; la Convención suplementaria sobre la abolición de la esclavitud, la trata de esclavos y las instituciones y prácticas análogas a la esclavitud (30 de Abril de 1956), Art. 3-1 ("El acto de transportar o de intentar transportar esclavos de un país a otro por cualquier medio de transporte, o la complicidad en dicho acto, constituirá delito en la legislación de los Estados Partes en la Convención, y las personas declaradas culpables de él serán castigadas con penas muy severas."); la Convención Internacional sobre la Eliminación de todas las Formas de Discriminación Racial (21 de diciembre de 1965). Art. 4 ("Los Estados partes (...) tomarán, entre otras, las siguientes medidas: a) Declararán como acto punible conforme a la ley toda difusión de ideas basadas en la superioridad o en el odio racial, toda incitación a la discriminación racial, así como todo acto de violencia o toda incitación a cometer tales actos contra cualquier raza o grupo de personas de otro color u origen étnico, y toda asistencia a las actividades racistas, incluida su financiación; b) Declararán ilegales y prohibirán las organizaciones, así como las actividades organizadas de propaganda y toda otra actividad de propaganda, que promuevan la discriminación racial e inciten a ella, y reconocerán que la participación en tales organizaciones o en tales actividades constituye un delito penado por la ley;"); la Convención de las Naciones Unidas contra la Tortura y Otros Tratos o Penas Crueles Inhumanas o Degradantes (10 de Diciembre de 1984), Art. 3-1, 2 (“Todo Estado Parte velará porque todos los actos de tortura constituyan delitos conforme a su legislación penal. Lo mismo se aplicará a toda tentativa de cometer tortura y a todo acto de cualquier persona que constituya complicidad o participación en la tortura. / Todo Estado Parte castigará esos delitos con penas adecuadas en las que se tenga en cuenta su gravedad." (Art. 3-1, 2); la Convención Interamericana para Prevenir y Sancionar la Tortura (9 de Diciembre de 1985), Art. 6-2 ("Los Estados partes se asegurarán de que todos los actos de tortura y los intentos de cometer tales actos constituyan delitos conforme a su derecho penal, estableciendo para castigarlos sanciones severas que tengan en cuenta su gravedad."
} 
pierde su prerrogativa de determinación en la selección del medio de satisfacción del fin de protección de esos intereses.

La determinación del exacto alcance de esta pérdida de prerrogativa de decisión de política legislativa es una cuestión eminentemente incierta. Para un adecuado tratamiento de este problema es necesario distinguir entre (a) deberes de incriminación, (b) deberes moderados de tipificación y (c) deberes extremos de tipificación.

El fundamento de esta distinción se basa en la constatación de que las relaciones arriba expuestas entre deberes de protección, deberes de regulación, deberes de sanción y deberes de punición se producen en el nivel del sentido normativo de los enunciados prescriptivos fijados en textos autoritativos. En tanto consecuencia de un deber de protección, un deber de regulación impone el deber de realizar actos normativos, pero no exige transcribir oraciones de un texto autoritativo del derecho internacional a un texto autoritativo del derecho interno. Si se analiza el establecimiento de normas como un acto de habla, lo que este sistema de relaciones normativas exige es congruencia entre los distintos actos de establecimiento de normas en su dimensión de actos proposicionales e ilocucionarios, pero no identidad en el nivel de su condición de actos de emisión.

Por "incriminación" propongo entender el acto de establecimiento de una norma punitiva, en su nivel de acto ilocucionario. En virtud de lo anterior, propongo denominar "deber de incriminación" al deber de punición que es vinculante en sus niveles de acto proposicional e ilocucionario, es decir, a su concepción como un acto ilocucionario que mienta otro acto ilocucionario y su referencia. Conforme a esto, cabe afirmar que: (a) salvo expresión inequívoca en contrario, todo deber de punición es simplemente un deber de incriminación, y que, en todo caso (b) a partir de un deber de protección sólo se puede llegar a justificar un deber de incriminación. Esto último es así, porque lo que el deber de protección impone al legislador es el imperativo de prevenir la afectación de intereses o estados de cosas, esto es, del objeto de referencia de las normas que consagran derechos fundamentales.

De este modo, el deber de incriminación exige -siempre bajo la prohibición de exceso que se deriva del principio de proporcionalidad- que cierto comportamiento se encuentre descrito como supuesto de hecho de un enunciado que impute una sanción penal como consecuencia de ese comportamiento. En la medida en que diversas palabras o frases pueden tener una misma referencia, el deber de incriminación no impone la obligación de utilizar determinadas frases o palabras. La elección de la fórmula lingüística es prerrogativa del legislador.

Desde luego, no existe otro medio que el lenguaje para identificar el objeto de referencia de un término o expresión lingüística. Las reglas de la semántica y la sintaxis establecen por lo tanto límites a las prerrogativas del legislador en su elección de la fórmula que ha de fijarse en el texto autoritativo del derecho 
doméstico. Desde un punto de vista semántico, puede decirse que el deber de incriminación exige una congruencia entre el texto autoritativo supralegal y el texto autoritativo doméstico, tal que el núcleo de significado positivo de la expresión del texto supralegal quede comprendido en el núcleo de significado positivo del texto legal.

Lo que se predica de la relación entre los términos de uno y otro texto cabe predicarlo también del sentido de uno y otro contexto. Debe existir también una congruencia en lo esencial de las representaciones simbólicas del derecho supralegal al que pertenece el deber de incriminación y el derecho legal en el cual se le da cumplimiento (función expresiva de la norma punitiva). Esto incluye dos aspectos fundamentales, que son el fin de protección de la norma y la importancia social de la prohibición de su afectación. El primer aspecto incide en la decisión de cuestiones sistemáticas y el segundo en la determinación del marco penal legal.

Dado el carácter de acto de habla del establecimiento de un deber de punición y su cumplimiento mediante el establecimiento de una norma punitiva, es lógica y prácticamente posible que el primero imponga deberes en el nivel de actos de emisión que cada uno de ellos tiene.

Un deber de congruencia en el nivel de actos de emisión admite satisfacción en un grado elemental, que se encuentra en la calificación del objeto de referencia. Esto consiste en que en el contexto del texto autoritativo de rango legal exista una unidad lingüística irreductible, inequívocamente correlacionable con la unidad lingüística del texto autoritativo supralegal. En el contexto dado por las relaciones entre un deber de punición internacional y el conjunto de las normas punitivas internas, por ejemplo, esa unidad lingüística irreductible es el supuesto de hecho de la norma sancionatoria, es decir, aquello que la doctrina penal de habla española designa como "tipo" al traducir el término alemán "Tatbestand".

La exigencia elemental en el nivel de actos de emisión consiste, pues, en que el derecho legal contemple un tipo penal, identificable como delito sui generis o autónomo dentro del catálogo de conductas punibles, el cual desde luego debe estar configurado mediante un enunciado que satisfaga las exigencias de congruencia en el nivel proposicional e ilocucionario. Esta exigencia básica puede entenderse que implica también una exigencia de congruencia particularmente estrecha en la denominación del delito. Pues el reconocimiento pleno del supuesto de hecho como unidad irreductible dentro del contexto del derecho interno requiere la existencia de un nombre exclusivo de ese supuesto de hecho. La congruencia en la calificación exige también un título de calificación (nomen iuris). A un deber que impone estas exigencias en el nivel de acto de emisión del establecimiento de la norma punitiva. Propongo denominarlo "deber moderado de tipificación”.

El grado máximo de congruencia en el nivel de actos de emisión consistiría sin embargo en un deber de transcribir los términos y expresiones del 
texto autoritativo supralegal en el texto autoritativo legal. Propongo denominar "deber extremo de tipificación" a un deber supralegal de tipificación que impone esta exigencia de transcripción.

Frente a los textos autoritativos supralegales que contengan deberes de tipificación, la pregunta crucial para la evaluación de su cumplimiento por el legislador es, pues, si se trata de deberes moderados o extremos de tipificación. Esta es básicamente una cuestión interpretativa de los textos internacionales y constitucionales que impongan tales deberes. Por tal razón, su solución es contingente. No obstante, debe asumirse que la cuestión interpretativa tiene lugar bajo un principio general de preferencia por la interpretación del imperativo como un deber moderado de tipificación. Este principio general se basa en tres órdenes de consideraciones.

(1) La exigencia moderada es manifiestamente funcional al fin del deber de tipificación, mientras que la exigencia extrema conlleva altos riesgos de disfuncionalidad. Esto es así, porque la operatividad de la norma punitiva establecida en cumplimiento del deber de tipificación decrece en forma directamente proporcional a la medida en que los términos y expresiones del texto autoritativo supralegal no correspondan a los términos y expresiones usuales del derecho legal. Dejar al legislador un margen importante de flexibilidad en la elección de la fórmula lingüística redunda en beneficio de la realización del fin del deber de punición.

(2) Es el caso que en la determinación de la fórmula lingüística a utilizarse en la configuración del supuesto de hecho de una norma punitiva se encuentran involucradas también la realización del principio de la proporcionalidad y la satisfacción óptima de todo el complejo de consideraciones propias del juicio acerca del merecimiento de pena. Es necesario distinguir a este respecto entre el contexto de fundamentación del juicio sobre el merecimiento de pena y el contexto de aplicación de ese juicio. El primero corresponde a la cuestión de justificar la decisión de incriminar un comportamiento. El segundo, a la cuestión de implementar o concretar institucionalmente esa decisión. La existencia de un deber supralegal de punición resuelve ciertamente la interrogante acerca del merecimiento de pena en el contexto de fundamentación de la decisión de ejercer el ius puniendi. Además, cuando ese deber asume la forma de un deber de tipificación, sus exigencias moderadas resuelven también una importante cantidad de cuestiones pertenecientes al contexto de aplicación de esa decisión. Con todo, ello no precluye la posibilidad de que surjan otras dificultades o interrogantes en este contexto, cuya adecuada solución requiere la consideración de los distintos puntos de vista pertinentes para el juicio de merecimiento de pena. La satisfacción de esta exigencia presupone un marco de flexibilidad en la determinación de la fórmula lingüística.

(3) Debe tenerse presente que la determinación de la fórmula lingüística a utilizarse en la configuración del supuesto de hecho de una norma punitiva es una 
cuestión sujeta a principios jurídicos que operan como límites a las posibilidades de expresión del legislador. El principio de legalidad y el principio de culpabilidad son los dos principales estándares normativos que cumplen esta función. Esto vale también para el derecho internacional. La asunción de estos dos estándares como principios implica que no sólo debe cuidarse de no infringirlos abiertamente, sino que además debe buscarse su optimización. La satisfacción de este postulado de optimización requiere necesariamente de un marco de flexibilidad en la determinación de la fórmula lingüística.

Las tres consideraciones conducen, como se ha dicho, a poner la carga de la prueba argumentativa del lado de la pretensión de interpretar un deber de tipificación como un deber que impone exigencias extremas. Estas consideraciones han sido expuestas en un orden creciente de conclusividad y peso específico.

La consideración (1), es completamente reversible, si en algún caso concreto resulta manifiesta la finalidad de imponer exigencias extremas de un mandato de tipificación. En tal caso, la decisión internacional cuenta como asunción deliberada del riesgo de disfuncionalidad en relación con sus propios fines. La reversibilidad de la consideración (2) es más difícil, en la medida en que ella no se mueve exclusivamente en el plano de la coherencia interna de la política criminal del derecho internacional, sino que involucra la aplicación de principios y argumentos políticos y morales.

La consideración de mayor peso es sin duda la (3), pues ella demuestra que la falta de reconocimiento de un margen de flexibilidad en la determinación de las fórmulas lingüísticas a ser utilizadas por el legislador puede llegar a originar una impugnación de la validez o legitimidad del propio mandato de tipificación. En tal caso, antes de invalidar el mandato internacional, en virtud del principio de conservación debe sin duda preferirse su interpretación como mandato moderado de tipificación.

Lo anterior tiene consecuencias prácticas ulteriores, para el caso en que se considere que un deber de tipificación no impone exigencias extremas. La diferencia de peso específico de las tres razones antedichas debe traducirse en una diferenciación de los grados de amplitud o flexibilidad del marco de decisión discrecional en torno a la determinación de la fórmula lingüística que ha de ser reconocido al legislador. El deber de tipificación tolera un mayor grado de divergencia entre el texto internacional y el texto doméstico en la misma medida en que sea mayor el peso específico de las razones invocadas por el legislador para justificar su elección de la fórmula lingüística.

\subsection{Problemas originados por la definición supralegal del merecimiento de pena.}

Son múltiples los problemas prácticos que presenta la existencia de definiciones supralegales de merecimiento de pena cada vez más específicas, 
manteniéndose sin embargo intactas las dificultades de su procedimiento de reforma. Estos problemas son particularmente graves en el derecho penal internacional, donde por la naturaleza de su génesis es prácticamente impensable la codificación.

Quizás no haya mejor ejemplo de la inmodificabilidad de las definiciones irracionales que el delito de genocidio. Surgida de la constatación de los crímenes cometidos bajo el régimen nacionalsocialista alemán, la regulación del genocidio establecida por la Convención para la Prevención y Sanción del Delito de Genocidio aprobada por las Naciones Unidas el 9 de Diciembre de 1948, y con entrada en vigor el 12 de Enero de 1951, ha sido tradicionalmente criticada por sus restricciones subjetivas y por la exclusión de los grupos políticos de aquellos que son objeto idóneo de ataque genocida ${ }^{4}$. Pero el problema político más grave de esta convención es que el concepto de genocidio es intrínsecamente discriminatorio. Pues aún en su versión más amplia sólo puede incluir grupos que tengan una identidad colectiva que se transmite generacionalmente. ¿Cómo puede valorarse la perduración de esa identidad en mayor medida que la supervivencia de una gran cantidad de personas, o incluso de una sola? Con ocasión del Estatuto de Roma pudo haberse disuelto este concepto en la categoría mejor definida de los crímenes contra la humanidad. Ello no ocurrió así: se dio primacía a la "conquista" que significó esa convención por sobre la racionalidad regulativa.

Otra fuente inagotable de problemas es encuentra en la configuración de las reglas que definen las condiciones generales de la tipificación de los delitos, como la imputación subjetiva (mens rea), la autoría y participación (parties of the crime) y el iter críminis (anticipatory ofences). Aún no existe -suponiendo que su existencia sea posible- un marco de conmensuración de las diferencias existentes entre los distintos sistemas jurídicos, que haga posible la "traducción" de esas definiciones en los términos de cada uno de ellos. Y éstas no son cuestiones accesorias: en ellas se juega, las más de las veces, la operatividad de la prosecución y la vigencia del principio de legalidad. La peor parte la lleva, naturalmente, el principio de legalidad.

Aquí radica uno de los problemas más delicados del desarrollo de un derecho penal fundamentado en deberes fundamentales de punición o

\footnotetext{
${ }^{4}$ Los Arts. II y III definen el crimen de genocidio y su ámbito de punibilidad, del siguiente modo: "Art. II. En la presente Convención, se entiende por genocidio cualquiera de los actos mencionados a continuación, perpetrados con la intención de destruir, total o parcialmente, a un grupo nacional, étnico, racial o religioso, como tal: (a) matanza de miembros del grupo; (b) lesión grave a la integridad física o mental de los miembros del grupo; (c) sometimiento intencional del grupo a condiciones de existencia que hayan de acarrear su destrucción física, total o parcial; (d) medidas destinadas a impedir los nacimientos en el seno del grupo; (e) traslado por fuerza de niños del grupo a otro grupo." "Art. III. Serán castigados los actos siguientes: (a) el genocidio; (b) la asociación para cometer genocidio; (d) la instigación directa y pública a cometer genocidio; (c) la tentativa de genocidio; (e) la complicidad en el genocidio."
} 
definiciones fundamentales de merecimiento de pena: en la erosión de los principios limitadores del ius puniendi.

Que el surgimiento del derecho penal internacional fue acompañado históricamente por la erosión del principio de legalidad, eso es un dato innegable. Basta con echar una mirada a las convenciones internacionales sobre derechos humanos para advertir su degradación en un principio de juridicidad, impotente para restringir el sistema de fuentes del derecho internacional. Uno de los rasgos más interesantes de la génesis del Estatuto de Roma fue el intento por asignar al principio de legalidad, en su función de vinculación de la condena a una disposición estatutaria (nullum crimen nulla poena sine lege scripta y stricta), el rol que tiene en la cultura jurídica europea continental ${ }^{5}$. Ello queda inmediatamente compensado, sin embargo, por la validación expresa que el Estatuto hace del sistema total de fuentes del derecho penal internacional ${ }^{6}$. Además, lo que se avanza en el sistema de fuentes del Estatuto, se retrocede en las exigencias de determinación (prohibición de vaguedad) de sus disposiciones. El Estatuto no sólo omite consagrar ese principio, sino que emplea la más clásica de las técnicas legislativas violatorias del mismo, como es la consagración de una cláusula general residual de carácter analógico?

No menos inquietantes son las infracciones del principio de culpabilidad, de presunción de inocencia y del derecho a no declarar contra sí mismo, en que incurre la tristemente célebre contribución de Latinoamérica a los crímenes contra la humanidad: el delito de desaparición forzada de personas. De todas las formulaciones de este concepto, la más gravemente vulneratoria de las garantías antedichas es precisamente aquélla que impone un deber más escrito de punición, la consagrada en la Convención Interamericana sobre Desaparición Forzada de Personas, de 9 de Julio de $1994^{8}$.

\footnotetext{
${ }^{5}$ El Estatuto de Roma de la Corte Penal Internacional establece una garantía de nullum crimen sine lege scripta (Art. $22 \mathrm{~N}^{\circ} 1$ ), stricta (Art. $22 \mathrm{~N}^{\circ}$ 2) y previa (Art. $22 \mathrm{~N}^{\circ} 1,24$ ), y una garantía de nulla poena sine lege scripta (Art. 23).

${ }^{6}$ Arts. 10 y $22 \mathrm{~N}^{\circ} 3$

7 Art. 7-1-11): “...se entenderá por crimen contra la humanidad cualquiera de los actos siguientes $(\ldots):$ k) Otros actos inhumanos de carácter similar que causen intencionalmente grandes sufrimientos o atenten gravemente contra la integridad física o la salud mental o física."

${ }^{8}$ La Convención entró en vigor con fecha de 29 de Marzo de 1996. Su Art. II dispone lo siguiente: "Para los efectos de la presente Convención, se considera desaparición forzada la privación de la libertad de una o más personas, cualquiera que fuere su forma, cometida por agentes del Estado o por personas o grupos de personas que actúen con la autorización, el apoyo o la aquiescencia del Estado, seguida de la falta de información o de la negativa a reconocer dicha privación de libertad o de informar sobre el paradero de la persona, con lo cual se impide el libre ejercicio de los recursos legales y de las garantías procesales pertinentes." La parte final de su Art. III dispone que "Dicho delito será considerado como continuado o permanente mientras no se establezca el paradero de la víctima”.
} 
El concepto de desaparición forzada de personas se basa en otro concepto, que no es problemático para el principio de culpabilidad: la privación de libertad. Lo que caracteriza la desaparición forzada es la omisión de las garantías fundamentales de la seguridad del detenido. Esto autoriza a considerar sin más la privación de libertad como un caso grave". Pero más allá de este efecto, no puede asociarse consecuencias punitivas a la "falta de información", o la "negativa a reconocer (la) privación de libertad", o la (negativa) "de informar sobre el paradero de la persona”. ¿Cómo podría, en efecto, sancionarse al acusado de un delito por no informar sobre el mismo? ¿En qué puede fundarse una agravación de la pena de la privación de libertad, si no es (ilegítimamente) en una sospecha de homicidio?

El derecho penal no puede tratar al agente del Estado que ha cometido un delito grave sino como un autor de un delito. Si algún deber de garante surge de su actuar (ingerencia), ese se relaciona con la evitación de ulteriores resultados lesivos típicamente relevantes. Pero no puede surgir de allí un deber de poner término a la privación de libertad distinto de su prohibición penal (ne bis in idem), ni tampoco uno de delatarse o brindar información acerca del delito cometido.

De lo dicho no se desprende que la desaparición forzada de personas sea un concepto espúreo para todos los efectos jurídicos concebibles. Desde el punto de vista de los procedimientos judiciales de amparo nacionales e internacionales, no cabe duda que la fundada presunción de la comisión de una detención, seguida por la negativa del funcionario imputado de reconocer el hecho o dar información sobre el detenido, debe poner en marcha las formas más drásticas de intervención judicial, para la investigación inmediata del hecho y la protección de la persona privada de libertad frente a un eventual asesinato o tortura. El gatillamiento de las medidas preventivas no requiere más que esas presunciones.

La justificación de la condena sin embargo, requiere un quantum más estricto de prueba y la satisfacción de todas las garantías procesales y sustantivas. $\mathrm{Si}$ las presunciones reunidas, alcanza ese quantum sin infringir esas garantías, entonces lo que corresponde es la condena por grave privación de libertad y homicidio calificado, o el tipo complejo que consuma el concurso ideal o material (secuestro con homicidio). Si ese no es el caso, entonces la condena sólo puede tener lugar por privación de libertad, habiendo prueba suficiente. No hay una tercera posibilidad legítima.

Tan escandalosa como la pretensión de tipificar un injusto con elementos incompatibles con garantías fundamentales es la regla de presunción de

\footnotetext{
${ }^{9}$ Esto es importante para las codificaciones penales que descienden del Código de Napoléon de 1810, como las sudamericanas del Siglo XIX. Lo característico del Código Napoleón en este ámbito es la concesión de un trato penal privilegiado al funcionario público. La infracción de las principales garantías de la seguridad del detenido debe ser considerada como un hecho que excluye la aplicación de este trato privilegiado.
} 
permanencia o continuidad a partir de la falta de noticias sobre el detenido. En tanto privación de libertad, el delito es permanente de por sí. Es decir, durante todo el tiempo en que se acredite que el detenido estuvo bajo el poder del funcionario, éste permaneció consumando el delito, sin necesidad de vincular la posibilidad de permanencia a la inexistencia de información sobre el destino de la víctima ${ }^{10}$. Para que la regla tenga sentido, es necesario interpretarla como una presunción de permanencia efectiva del delito. Pero la diferencia entre el carácter permanente de un delito y su permanencia efectiva en un caso concreto es tan grande como la que existe entre el carácter comisible de un delito y su efectiva comisión en un caso concreto. Presumir a partir de la inexistencia de noticias del detenido, es decir, de la ausencia de prueba acerca del curso posterior de la detención, que la privación de libertad sigue permaneciendo, viola igualmente las garantías antedichas.

Para terminar con este breve recuento de dificultades, conviene mencionar la que constituye la expresión más fiel de la inversión de paradigmas, y que se encuentra en la tendencia irracionalmente expansiva de la punibilidad de la agenda de protección de los derechos fundamentales. Dos ejemplos, especialmente significativos para la política criminal ilustrada, bastan para hacerla evidente.

El primero se encuentra en el reciente Protocolo Facultativo de la Convención sobre los Derechos del Niño relativo a la venta de niños, la prostitución infantil y la utilización de niños en la pornografía ${ }^{11}$. El propósito central del protocolo es la prohibición bajo pena de la venta de seres humanos, su explotación sexual o la afectación de su indemnidad sexual. Este no es un fin de protección ajeno al núcleo del derecho penal legítimo. Sus alcances concretos exceden sin embargo ese marco. La punición de las acciones de "ofrecer un niño" para la realización de acciones prohibidas con él [Art. 3-1-a)-i, y b)], "inducir indebidamente (...) a alguien a que preste su consentimiento para la adopción de un niño en violación de los instrumentos jurídicos internacionales aplicables en materia de adopción" [Art. 3-1-a)-ii], y de "ofrecer o poseer (con el fin de ofrecer) material pornográfico en que se utilicen niños" [Art. 3-1-c)] no es una consecuencia necesaria del merecimiento de pena de la realización efectiva de las acciones prohibidas con el niño, la infracción efectiva de algunas de las normas de los instrumentos internacionales o el involucramiento del menor en una interacción de significación sexual con ocasión de la producción de pornografía. Es más, en este último punto el Protocolo ni siquiera diferencia la producción de pornografía que sometió al menor a esa clase de interacción de la que no lo hizo.

\footnotetext{
10 Su calificación como "continuado" es producto de una deficiente compresión de los redactores del texto internacional. El concepto de delito continuado se aplica a casos en que en principio podrían calificarse como un concurso real. La caracterización de la privación de libertad como delito permanente excluye conceptualmente la posibilidad de esa calificación.

11 Consultado en la página del Alto Comisionado de las Naciones Unidas para los Derechos Humanos (http://www.unhchr.ch/spanish/html/menu2/dopchild sp.htm.: última visita el 30 de Marzo de 2001.
} 
Finalmente, dado que el Protocolo maneja el concepto de niño de la Convención ${ }^{12}$, impone un mandato de punición sin distinguir entre la condición púber o impúber del menor de dieciocho años. Esto significa suprimir de un plumazo las diferencias de fundamentación política del merecimiento de pena del comportamiento sexual elaboradas por la política criminal liberal europea.

El segundo caso se encuentra en la regulación del acoso sexual. Este es un concepto con el cual se designa diversas formas de comportamiento ofensivo para la persona acosada. La cuestión de si utilizar o no el derecho penal como herramienta para prevenir estas formas de comportamiento es una cuestión abierta en la política criminal comparada, existiendo buenas razones para la respuesta negativa ${ }^{13}$. La reciente Convención Interamericana para prevenir, sancionar y erradicar la violencia contra la Mujer ${ }^{14}$ considera sin embargo al acoso sexual un acto de violencia contra la mujer, equiparándolo a la tortura, la violación y el secuestro ${ }^{15}$. Esta equiparación es relevante a la luz de los deberes de regulación, sanción y punición impuestos por la Convención, que son amplios ${ }^{16}$. Nuevamente, la agenda internacional echa por la borda las diferenciaciones que la política criminal europea ha venido acuñando desde el Siglo XVIII para controlar la manipulación moralizante de la pena.

\footnotetext{
12 Art. 1. "Para los efectos de la presente Convención, se entiende por niño todo ser humano menor de dieciocho años de edad, salvo que, en virtud de la ley que le sea aplicable, haya alcanzado antes la mayoría de edad."

${ }^{13}$ Los argumentos contrarios a la recepción penal del concepto de acoso sexual como definición de un delito son cuatro: (a) que el acoso coercitivo ya es punible en el sistema como coacción mediante amenaza (amenaza condicional), (b) que en todo caso el acoso coercitivo no satisface los requisitos estructurales del sistema de los delito de atentado sexual (gravedad del medio comisivo y acaecimiento del resultado), (c) que el concepto de acoso ambiental no satisface las exigencias del principio de legalidad, y (d) que su tratamiento en el derecho del trabajo es suficiente e incluso preferible como estrategia de política jurídica.

14 Convención de Belem do Pará, aprobada por la Asamblea General de la Organización de Estados Americanos el 9 de Junio de 1994.

15 Artículo 2-b): "Se entenderá que violencia contra la mujer incluye la violencia física, sexual y psicológica: a. (...)que tenga lugar dentro de la familia o unidad doméstica o en cualquier otra relación interpersonal, ya sea que el agresor comparta o haya compartido el mismo domicilio que la mujer, y que comprende, entre otros, violación, maltrato y abuso sexual; b. que tenga lugar en la comunidad y sea perpetrada por cualquier persona y que comprende, entre otros, violación, abuso sexual, tortura, trata de personas, prostitución forzada, secuestro y acoso sexual en el lugar de trabajo, así como en instituciones educativas, establecimientos de salud o cualquier otro lugar, (...)".

16 Artículo 7. Los Estados Partes condenan todas las formas de violencia contra la mujer y convienen en adoptar, por todos los medios apropiados y sin dilaciones, políticas orientadas a prevenir, sancionar y erradicar dicha violencia y en llevar a cabo lo siguiente: (...) c. incluir en su legislación interna normas penales, civiles y administrativas, así como las de otra naturaleza que sean necesarias para prevenir, sancionar y erradicar la violencia contra la mujer y adoptar las medidas administrativas apropiadas que sean del caso; d. adoptar medidas jurídicas para conminar al agresor a abstenerse de hostigar, intimidar, amenazar, dañar o poner en peligro la vida de la mujer de cualquier forma que atente contra su integridad o perjudique su propiedad; (...)”.
} 
De los tres problemas apuntados, el más fácil de enfrentar argumentativamente es el de la erosión de las garantías fundamentales. Pues es claro que la evidencia moral o política en torno al merecimiento de pena de un comportamiento no produce efecto alguno en relación con las exigencias negativas de legitimación del ius puniendi, desde el principio de legalidad hasta el principio de culpabilidad. Estos no son requisitos aplicables al control de las decisiones infundadas, arbitrarias o moralmente controvertibles del legislador en materia de punición. El control del déficit de racionalidad es brindado por la garantía específica de la última ratio, basada en el principio de la proporcionalidad. Las demás garantías son aplicables a las pretensiones de ejercicio del ius puniendi que satisfacen esta garantía específica. Esa satisfacción -y nada más- es la consecuencia de un mandato supralegal explícito de punición. Los límites que el Estado de Derecho impone al establecimiento de una norma punitiva deben ser asumidos como límites oponibles también al mandato de punición. Las relaciones entre los principios garantísticos del Estado de Derecho y la política criminal son tales que la evidencia moral o el consenso político en torno al merecimiento de pena de un comportamiento nunca puede disminuir las exigencias impuestas por los principios de legalidad y culpabilidad.

El problema de la irracionalidad sistemática y el de la irracionalidad político-criminal no son tan fácilmente contrarrestables mediante argumentos. Esto es así porque nuestra cultura política concibe la definición del merecimiento de pena como la expresión de una voluntad normativa. Así se lo ha asumido en estas páginas, con la tesis de la inderivabilidad de normas punitivas a partir de normas de comportamiento. De aquí que un quantum de prerrogativa de decisión discrecional sea inevitable, incluyendo posibles déficit de racionalidad. Si el sistema jurídico transfiere esa prerrogativa de decisión, del soberano local a instancias internacionales, hay que reconocer a esta instancia un margen de discrecionalidad semejante. La corrección del déficit de racionalidad sistemática o político-criminal sólo puede producirse en el margen de discrecionalidad que a su vez deje la definición supralegal al soberano local para su implementación en el derecho interno. Esta es una razón para el principio de interpretación preferente de los deberes de punición como deberes de incriminación, o en su defecto, como deberes moderados de tipificación.

\section{Derechos fundamentales y necesidad de la ejecución de la pena}

Un comportamiento merecedor de pena, definido así por una norma que satisface las exigencias de las garantías limitadoras del ius puniendi, es en principio necesitado de pena. La constatación de un comportamiento necesitado de pena hace necesaria la ejecución de esa pena. El tratamiento de las consideraciones excepcionales que pueden justificar la exención de pena, o la prescindencia de su ejecución, con o sin medidas sustitutivas, pertenece a la teoría de la determinación de la pena y a la regulación concreta de cada sistema jurídico. 
Sin embargo, son usuales en los sistemas jurídicos ciertos procedimientos o instituciones que pueden contrarrestar esta necesidad de la ejecución de la pena. La amnistía y el indulto son esos procedimientos; la prescripción de la acción penal o de la pena, esas instituciones. Esto hace que el juicio de necesidad de la ejecución de la pena sea provisorio.

Lo que se expresa a través de estos procedimientos e instituciones, contrarrestando el juicio de necesidad de la pena, son consideraciones de racionalidad conforme a fines, es decir, de falta de necesidad preventiva (prospectiva) de la pena. Ciertamente, el indulto puede responder a otra justificación, incluso retrospectiva. Eso no interesa aquí: lo relevante para los delitos contra los derechos fundamentales es la cuestión de la tensión entre el juicio de necesidad de ejecución de la pena, fundado retrospectivamente, y el eventual juicio prospectivo de falta de esa necesidad.

La mejor fundamentación disponible de la fundamentación retrospectiva de la necesidad de la ejecución de la pena se encuentra en la teoría del funcionalismo retribucionista. Siguiendo a Hegel, esta teoría atribuye a la infracción de la norma de comportamiento un sentido normativo negador de la vigencia de la norma infringida, y a su reproche mediante la pena, el sentido de la afirmación de esa vigencia. La pena es así autoconstatación del orden normativo.

La debilidad de esta fundamentación radica en que la atribución de un sentido normativo (o cuasi normativo) a la infracción a la norma depende de la forma o clase de vigencia que tenga esa norma. En un sistema simple de normas, carente de reglas de reconocimiento asociadas a reglas de cambio, la desviación puede interpretarse como negación de la vigencia. Pero en un sistema normativo reflexivo, en el cual el reconocimiento de la norma es provisto por criterios procedimentales de validez, la infracción de la norma no puede ser interpretada como un acto con sentido normativo, sin contradecir al sistema normativo. Pues en él ese sentido está gobernado por reglas, y no hay una regla secundaria que le atribuya ese carácter. La concepción del derecho abstracto de Hegel, donde tiene lugar la fundamentación retribucionista de la pena como superación del delito, guarda un parecido más estrecho con un sistema normativo simple que con uno reflexivo. Su aplicación al contexto de un sistema normativo reflexivo, requiere por lo tanto una reinterpretación del sentido del delito.

El carácter de "atentado a un derecho fundamental" del delito no altera lo dicho anteriormente. Todo homicidio, lesión corporal, injuria o coacción violenta es un atentado contra un derecho fundamental. Y en un sistema jurídico reflexivo la comisión de esos delitos no son sin más interpretables como portadores de un sentido normativo. La reducción stricto sensu del concepto de delito contra los derechos fundamentales a los casos de comisión por funcionarios públicos apunta hacia la solución del problema. Pero su fundamentación como delitos especiales es inconsistente. Una vez que se atribuye a los derechos fundamentales la función de justificar normas de comportamiento erga omnes o deberes de establecimiento de 
esas normas, desaparece la prioridad de la prohibición de afectación destinada al Estado como deber correlativo.

El fundamento correcto de una concepción restrictiva de los crímenes contra derechos humanos se encuentra en un fenómeno que no puede ser expresado en el tipo penal: la impunidad. Los "delitos de impunidad" forman una clase de delitos inequívocamente portadora de ese sentido cuasi-normativo, incluso en un sistema jurídico reflexivo, que justifica la necesidad de la ejecución de la pena. Estos son los delitos contra intereses fundamentales, cometidos por personas vinculadas a las funciones de mantención de vigencia del orden establecido, en forma sistemática y/o generalizada, y bajo condiciones fácticas de impunidad conocidas y asumidas ex ante por los autores de esos delitos ${ }^{17}$. Estos delitos erosionan las expectativas normativas de los afectados en términos inequívocamente portadores de una redefinición del alcance del fin de protección de las normas de comportamiento, excluyendo de él los intereses del círculo de afectados. Cuando la norma es supuestamente fundamental, y su infracción reiterada por el responsable de su vigencia queda impune, y esa impunidad es un factor relevante para su comisión, la expectativa normativa de intangibilidad del círculo de afectados actuales y potenciales se hace insignificante frente a las expectativas cognitivas de peligro de afectación.

Frente a este fenómeno, una decisión legislativa posterior de prescindencia de la pena tiene inevitablemente el sentido de confirmación de la comunicación que portaban los delitos. Esta es la razón profunda de la inexorabilidad de la ejecución de la pena como procedimiento de solución del conflicto suscitado por estos casos. Así es como se logra negar institucionalmente la validez del mensaje cuasi-normativo de esos delitos, afirmando con ello la vigencia categórica, definitiva y universal de las normas fundamentales.

El rechazo de la operatividad de la amnistía y la prescripción tiene otro buen fundamento, cuando su génesis obedece al mismo fenómeno que hizo posible la comisión de esos delitos, es decir, en el manejo de un aparato organizado de poder, que operaba como irresistible. La amnistía que es autoexoneración, y la prescripción que es consecuencia de la omisión del mismo aparato de poder cuyos miembros cometieron los delitos no pueden contar, desde un punto de vista de la justicia política, como legítima solución alternativa al proceso penal y la condena ni como expresión de la falta de necesidad preventiva de la pena, respectivamente. Demás está decirlo, la autoexoneración mediante amnistía es la expresión formal ex post de la condición de delitos de impunidad. Y

\footnotetext{
${ }^{17}$ Con esta precisión distingo esta clase de delitos de los atentados a derechos fundamentales que de iure eran impunes al momento de su comisión. El tratamiento de esta cuestión exige la solución del conflicto entre los mandatos de punición y el principio de legalidad, tanto desde el punto de vista de las posibles excepciones a la prohibición de retroactividad desfavorable, como de la legitimidad de un derecho penal sin base convencional.
} 
la prescripción por omisión de prosecución, un elemento necesario de esa impunidad.

Pero la primera razón no excluye a priori que el efecto comunicativo de la pena pueda alcanzarse por otra vía institucional, y la segunda razón no conduce necesariamente a la declaración apriorística de la inamnistiabilidad e imprescriptibilidad de estos delitos.

La idea de la autoexoneración de responsabilidad puede desempeñar la función de límite inmanente al fundamento de las instituciones de la amnistía y la prescripción, que posibilitan el desarrollo de una concepción diferenciada de su validez. Es innegable que el desarrollo argumentativo y la implementación institucional de esta idea de la autoexoneración se enfrenta a arduas dificultades, en todos los casos de continuidad político-jurídica entre el régimen bajo el cual se cometieron los delitos y se amnistió o no se procesó y el régimen bajo el cual se formula la impugnación de esa amnistía o prescripción. En ambos casos es sumamente difícil determinar la naturaleza precisa de los impedimentos u omisiones de prosecución (prescripción) o de la conexión entre los autores de los hechos y los que actuaron como legisladores (amnistía). La impugnación de la prescripción conlleva una acusación, al menos de responsabilidad política, sobre los órganos encargados de la prosecución penal, que probablemente sigan en ejercicio de sus funciones. La impugnación de la amnistía se enfrenta al dilema de que su aceptación requerirá usualmente una evidencia que por lo general sólo podría obtenerse mediante el proceso, pero que éste requiere como presupuesto la punibilidad del objeto de investigación, la que naturalmente no puede afirmarse sin impugnar la amnistía.

El que la inamnistiabilidad y la imprescriptibilidad sean consideradas como más operativas se debe sin embargo a la falta de desarrollo en el derecho internacional y el derecho público comparado de categorías diferenciadas de presunciones de autoexoneración y de su consideración procesal como parte del objeto sobre el que debe (o puede) recaer prueba, junto con los demás elementos del delito. Semejante desarrollo podría hacer de la idea de los límites inmanentes a estas dos instituciones un principio satisfactoriamente operativo. Que el derecho internacional penal se haya abstenido de dar pasos en este sentido, prefiriendo afirmar la inexorabilidad de la pena, es un hecho lamentable para el desarrollo de la cultura jurídica global.

En lo que respecta a la posibilidad de expresar la vigencia de las normas infringidas por vías alternativas al reproche penal de la infracción, ella constituye la gran interrogante de una cultura que alega adherir al principio de la prioridad del respeto por los derechos fundamentales. Además, es una de las claves de análisis de los procesos de justicia transicional. Una revisión de la conducción de la política de los distintos procesos de transición que pusiera énfasis en este aspecto podría detectar que el gran déficit de orientación normativa originado por la impunidad se debió principalmente a la ausencia o falta de éxito de estrategias 
institucionales alternativas a la punición. $\mathrm{Y}$ es también una fuente de auténtica perplejidad. Cualquiera que lea las narraciones de las atrocidades del -francamente impresentable-Siglo XX no puede dejar de preguntarse cómo es que, enfrentada a ello, la humanidad permanece anclada a procedimientos institucionales de expresión de indignación, sin haber sido capaz de crear un procedimiento institucional de expresión definitiva y categórica de compasión. 